\title{
Rare Earth Elements and carbon nanotubes in coal mine around spontaneous combustions
}

\author{
Luis F. O. Silva; Tito J. Crissien; Bernardo F. Tutikian; Carlos H. \\ Sampaio
}

\section{Abstract}

Increasing population growth and rise global energy petition have made congregation the requests of energy generation and safety a major challenge global. In another hand nanogeoscience is commencing to develop a viable remediation approach of attention in coal mine drainage (CMD) around spontaneous coal combustion (SCC). On the ecological context, nanophases (minerals and/or amorphous phases) are more reactive than bulk compounds, a property that powerfully influences the fate of pollutants in topsoils and drainages. In this work petrographic and geochemical investigations of selected CMD sediments were conducted. The substitution of As, Cd, Hg, and Se in pyrite was most apparent in the CMD sediments. The sampled CMD contained carbon nanotube (CNTs) structures and many others C-nanophases. The CNTs contained several elements, including $\mathrm{Hg}, \mathrm{Pb}, \mathrm{F}, \mathrm{Cl}$, and halogens. While CNTs are known to be produced from coal fires of varying ranks, this seems to be the first report of naturally occurring CNTs. This work also denotes the occurrence of historical NPs-locations in near vicinity to all other, as for illustration deposits of C-NPs and non-crystalline compounds appear only nanometers separately from each other on the contradictory sides of nonaltered amorphous phases. In addition, non-conventional sources, including CMD hosting elevated concentrations of Rare Earth Elements and Yttrium (REY), have been explored as attractive secondary sources for elements recovery. Consequently, in this study we investigate CMD from abandoned coal mines in the South America as a potential REY resource. It is suggested that more work is required on CMD and a few research areas are proposed for future research.

Keywords: Carbon nanotubes; Potential hazardous elements; Spontaneous coal combustión; Potential hazardous elements; Sediments drainages 